Supporting Information for

\title{
Application of Fluorescence Microscopy for Investigation of Cellular Distribution of Dinuclear Platinum Anticancer Drugs
}

\author{
Ganna V. Kalayda, ${ }^{a}$ Guofang Zhang, ${ }^{a}$ Tsion Abraham, ${ }^{b}$ Hans J. Tanke, ${ }^{b *}$ and \\ Jan Reedijk ${ }^{a *}$ \\ ${ }^{a}$ Leiden Institute of Chemistry, Gorlaeus Laboratories, Leiden University, PO Box \\ 9502, 2300 RA Leiden, The Netherlands. \\ ${ }^{b}$ Laboratory for Cytochemistry and Cytometry, Department of Molecular Cell \\ Biology, Leiden University Medical Center, Wassenaarseweg 72, 2333 AL Leiden, \\ The Netherlands.
}

Table of Contents

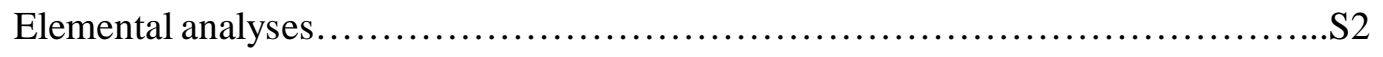

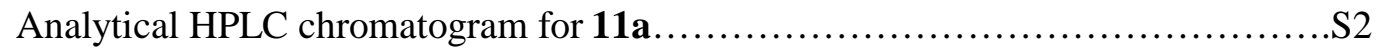

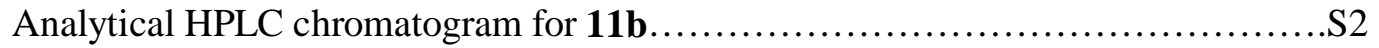


Elemental analyses

\begin{tabular}{|c|c|c|}
\hline compound & Calcd & Found \\
\hline $\mathbf{2}\left(\mathrm{C}_{22} \mathrm{H}_{54} \mathrm{~N}_{10} \mathrm{O}_{10} \mathrm{Cl}_{2} \mathrm{Pt}_{2}\right)$ & C: $24.47 ; \mathrm{H}: 5.04 ; \mathrm{N}: 12.97$ & C: $24.31 ; \mathrm{H}: 4.28 ; \mathrm{N}: 12.89$ \\
\hline $\mathbf{4 a}\left(\mathrm{C}_{62} \mathrm{H}_{66} \mathrm{~N}_{8} \mathrm{O}_{16} \mathrm{Cl}_{4} \mathrm{Pt}_{2}\right)$ & $\mathrm{C}: 43.52 ; \mathrm{H}: 3.89 ; \mathrm{N}: 6.55$ & C: $44.8 ; \mathrm{H}: 3.81 ; \mathrm{N}: 6.24$ \\
\hline $\mathbf{4 b}\left(\mathrm{C}_{36} \mathrm{H}_{64} \mathrm{~N}_{14} \mathrm{O}_{10} \mathrm{Cl}_{4} \mathrm{Pt}_{2}\right)$ & $\mathrm{C}: 31.22 ; \mathrm{H}: 4.66 ; \mathrm{N}: 14.16$ & C: $32.22 ; \mathrm{H}: 3.86 ; \mathrm{N}: 14.30$ \\
\hline $\mathbf{6}\left(\mathrm{C}_{9} \mathrm{H}_{10} \mathrm{~N}_{2} \mathrm{O}_{4} \mathrm{~F}_{6}\right)$ & $\mathrm{C}: 33.34 ; \mathrm{H}: 3.11 ; \mathrm{N}: 8.64$ & C: $32.95 ; \mathrm{H}: 3.03 ; \mathrm{N}: 8.67$ \\
\hline $\mathbf{7}\left(\mathrm{C}_{18} \mathrm{H}_{28} \mathrm{~N}_{4} \mathrm{O}_{5} \mathrm{~F}_{6}\right)$ & $\mathrm{C}: 43.73 ; \mathrm{H}: 5.71 ; \mathrm{N}: 11.33$ & C: $43.76 ; \mathrm{H}: 5.58 ; \mathrm{N}: 11.14$ \\
\hline $\mathbf{9}\left(\mathrm{C}_{14} \mathrm{H}_{42} \mathrm{~N}_{10} \mathrm{O}_{9} \mathrm{Cl}_{2} \mathrm{Pt}_{2}\right)$ & $\mathrm{C}: 17.60 ; \mathrm{H}: 4.43 ; \mathrm{N}: 14.66$ & C: $17.14 ; \mathrm{H}: 4.32 ; \mathrm{N}: 15.00$ \\
\hline
\end{tabular}

\section{Analytical HPLC chromatogram for 11a}

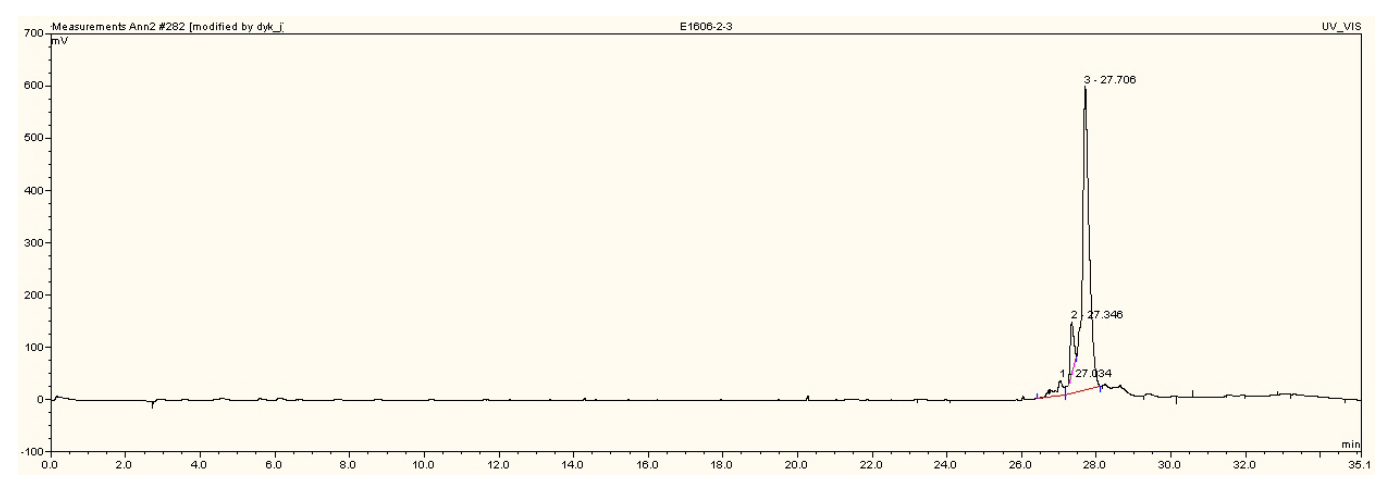

Analytical HPLC chromatogram for 11b

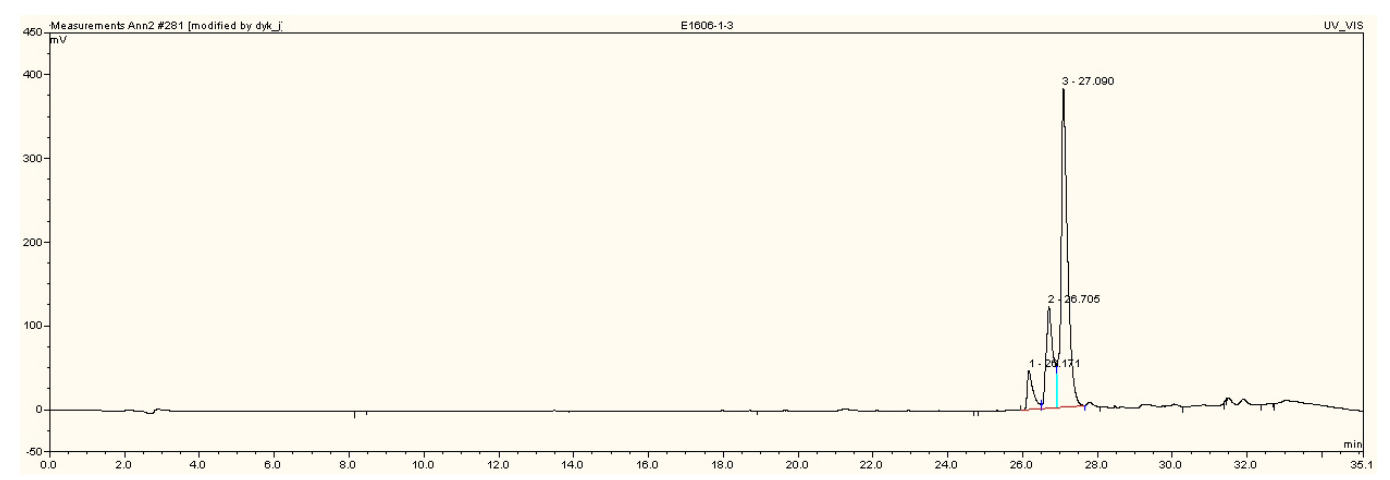

